\title{
Variational approach to impulsive differential system
}

\author{
Yanqiang $\mathrm{Wu}^{*}$ and Wenbin Liu
}

\section{"Correspondence:}

wyq1976819@126.com

College of Sciences, China

University of Mining and

Technology, Xuzhou, 221008, China

\begin{abstract}
In this work, we consider a nonlinear Dirichlet problem with impulses and obtain the existence of solutions to an impulsive problem by means of variational methods.
\end{abstract}

MSC: $34 \mathrm{~A} 08 ; 34 \mathrm{~B} 15$

Keywords: impulsive problem; Dirichlet condition; variational methods

\section{Introduction}

In this paper, we deal with the following impulsive differential system of the form

$$
\left\{\begin{array}{l}
-u^{\prime \prime}(t)+g(t) u(t)=f_{u}(u, v), \quad \text { a.e. } t \in[0, T], \\
-v^{\prime \prime}(t)+h(t) v(t)=f_{v}(u, v), \quad \text { a.e. } t \in[0, T], \\
u(0)=u(T)=v(0)=v(T)=0, \\
\Delta u^{\prime}\left(t_{k}\right)=u^{\prime}\left(t_{k}^{+}\right)-u^{\prime}\left(t_{k}^{-}\right)=I_{k}\left(u\left(t_{k}\right)\right), \\
\Delta v^{\prime}\left(t_{k}\right)=v^{\prime}\left(t_{k}^{+}\right)-v^{\prime}\left(t_{k}^{-}\right)=J_{k}\left(v\left(t_{k}\right)\right), \quad k=1,2, \ldots, m,
\end{array}\right.
$$

where $t_{0}=0<t_{1}<t_{2}<\cdots<t_{m}<t_{m+1}=T, g, h \in L^{\infty}[0, T], f_{u}, f_{v}: \mathbb{R}^{2} \rightarrow \mathbb{R}$ are continuous, and $I_{k}, J_{k}: \mathbb{R} \rightarrow \mathbb{R}, k=1,2, \ldots, m$, are continuous.

We point out that many dynamical systems have an impulsive dynamical behavior due to abrupt changes at certain instants during the evolution process. The mathematical description of these phenomena leads to impulsive differential equations. Based on the significance, a lot of developments have been made in the theory and applications of impulsive differential systems by numerous mathematicians. We refer the reader to the classical monograph (see $[1,2]$ ), the general works on the theory (see [3-10]) and applications of impulsive differential equations which occur in biology, control theory, optimization theory, population dynamics, medicine, mechanics, engineering and chaos theory, etc. (see [11-27]). These classical techniques contain fixed point theory, topological degree theory and comparison method (including monotone iterative method and upper and lower solutions methods).

For a second order differential equation $u^{\prime \prime}=f\left(t, u, u^{\prime}\right)$, one usually considers, as impulsive, the position $u$ and the velocity $u^{\prime}$. However, in the motion of spacecraft one has to deal with instantaneous impulses depending on the position that results in jump discontinuities in velocity, but no change in position (see [12, 28-30]). The impulses only on the velocity occur also in impulsive mechanics.

(c) 2015 Wu and Liu. This article is distributed under the terms of the Creative Commons Attribution 4.0 International License (http://creativecommons.org/licenses/by/4.0/), which permits unrestricted use, distribution, and reproduction in any medium, provided you give appropriate credit to the original author(s) and the source, provide a link to the Creative Commons license, and indicate if changes were made. 
Many problems can be solved in terms of the minimization of a functional, usually related to the energy, in an appropriate space of functions. The purpose of this work is to investigate the variational structure under the impulsive differential system (1.1). Based on variational method, we introduce a different concept of solution, that is, a weak solution to problem (1.1). The critical points of the corresponding functional are indeed weak solutions of the impulsive problem (1.1). For the impulsive Dirichlet boundary value problems, the known results obtained by variational approach and critical point theory are as follows.

In [31], to the best of our knowledge, Tian and Ge firstly study the impulsive differential problem by variational method. They deal with the following problem:

$$
\left\{\begin{array}{l}
\left(\rho(t) \phi_{p}\left(u^{\prime}(t)\right)\right)^{\prime}+s(t) \phi_{p}(u(t))=f(t, u(t)), \quad \text { a.e. } t \in[a, b] \\
\Delta\left(\rho\left(t_{j}\right) \phi_{p}\left(u^{\prime}\left(t_{j}\right)\right)\right)=I_{j}\left(u\left(t_{j}\right)\right), \quad j=1,2, \ldots, p \\
\alpha u^{\prime}(a)+\beta u(a)=A, \quad \gamma u(b)+\sigma u^{\prime}(b)=B
\end{array}\right.
$$

and essentially prove that when $f$ and $I_{j}$ satisfy some conditions, problem (1.2) has at least two positive solutions via variational method.

Nieto and O'Regan [32] consider the impulsive linear problem

$$
\left\{\begin{array}{l}
-u^{\prime \prime}(t)+\lambda u(t)=\sigma(t), \quad \text { a.e. } t \in[0, T] \\
u(0)=u(T)=0, \\
\Delta u^{\prime}\left(t_{j}\right)=u^{\prime}\left(t_{j}^{+}\right)-u^{\prime}\left(t_{j}^{-}\right)=d_{j}, \quad j=1,2, \ldots, p,
\end{array}\right.
$$

and the impulsive nonlinear problem

$$
\left\{\begin{array}{l}
-u^{\prime \prime}(t)+\lambda u(t)=f(t, u(t)), \quad \text { a.e. } t \in[0, T] \\
u(0)=u(T)=0, \\
\Delta u^{\prime}\left(t_{j}\right)=I_{j}\left(u\left(t_{j}\right)\right), \quad j=1,2, \ldots, p
\end{array}\right.
$$

where $d_{j}$ are constants, $I_{j}: \mathbb{R} \rightarrow \mathbb{R}, j=1,2, \ldots, p$, are continuous, $f:[0, T] \times \mathbb{R} \rightarrow \mathbb{R}$ is continuous. They exhibit the variational formulations for problems (1.3) and (1.4) and establish the existence and multiplicity of solutions using standard results of critical point theory. For more results, we refer the reader to [33-35].

In this paper we consider the impulsive nonlinear coupled differential system (1.1) motivated by the results [32-35]. Our main result extends the studies made in [32-35] in the sense that we are concerned with a class of problems that is not considered in the papers.

Throughout the paper, we need the following conditions.

$\left(\mathrm{H}_{1}\right)$ Assume that $\alpha>-\lambda_{1}$, where $\alpha=\min \left\{\operatorname{essinf}_{t \in[0, T]} g(t)\right.$, ess $\left.\inf _{t \in[0, T]} h(t)\right\}$ and $\lambda_{1}=\frac{\pi^{2}}{T^{2}}$ is the first eigenvalue of the problem

$$
\left\{\begin{array}{l}
-u^{\prime \prime}(t)=\lambda u(t), \quad t \in[0, T] \\
u(0)=u(T)=0
\end{array}\right.
$$

$\left(\mathrm{H}_{2}\right)$ There exist $a, b>0$ and $\gamma_{1}, \gamma_{2} \in[0,1)$ such that

$$
\left|f_{x}(x, y)\right| \leq a+b|x|^{\gamma_{1}} \quad \text { for every }(x, y) \in \mathbb{R}^{2}
$$


and

$$
\left|f_{y}(x, y)\right| \leq a+b|y|^{\gamma_{2}} \quad \text { for every }(x, y) \in \mathbb{R}^{2} \text {. }
$$

$\left(\mathrm{H}_{3}\right)$ There exist $a_{k}, b_{k}>0$ and $\beta_{k} \in[0,1)(k=1,2, \ldots, m)$ such that

$$
\left|I_{k}(u)\right| \leq a_{k}+b_{k}|u|^{\beta_{k}} \quad \text { for every } u \in \mathbb{R}
$$

and

$$
\left|J_{k}(v)\right| \leq a_{k}+b_{k}|v|^{\beta_{k}} \quad \text { for every } v \in \mathbb{R}
$$

The main result of this paper is the following.

Theorem 1.1 Let assumptions $\left(\mathrm{H}_{1}\right)-\left(\mathrm{H}_{3}\right)$ be satisfied. Then problem (1.1) has at least one nontrivial solution.

Obviously, Theorem 3.2 in [35] is a special case of Theorem 1.1 in this paper.

This paper is organized as follows. In Section 2, we introduce a Hilbert space $X=$ $H_{0}^{1}(0, T) \times H_{0}^{1}(0, T)$, on which the corresponding functional $\Phi$ of problem (1.1) is defined. Furthermore, we give some necessary notations and preliminaries. In Section 3, we prove the main result via variational approach.

\section{Variational structure}

Let $L^{p}[0, T]$ be the space formed by functions which are $p$-times integrable on $[0, T]$ under the norm

$$
\|u\|_{L^{p}}=\left(\int_{0}^{T}|u(t)|^{p} d t\right)^{\frac{1}{p}}
$$

and $C[0, T]$ be the space of all continuous functions on $[0, T]$ with the norm

$$
\|u\|_{\infty}=\max _{t \in[0, T]}|u(t)|
$$

In the Sobolev space $H_{0}^{1}(0, T)$, we consider the inner conduct

$$
(u, v)_{1}=\int_{0}^{T} u^{\prime}(t) v^{\prime}(t) d t
$$

and

$$
(u, v)_{2}=\int_{0}^{T} u(t) v(t) d t+\int_{0}^{T} u^{\prime}(t) v^{\prime}(t) d t
$$

which induce the corresponding norms

$$
\|u\|_{1}=\left(\int_{0}^{T}\left|u^{\prime}(t)\right|^{2} d t\right)^{\frac{1}{2}}
$$


and

$$
\|u\|_{2}=\left(\int_{0}^{T}|u(t)|^{2} d t+\int_{0}^{T}\left|u^{\prime}(t)\right|^{2} d t\right)^{\frac{1}{2}}
$$

By Poincaré’s inequality,

$$
\lambda_{1} \int_{0}^{T} u^{2}(t) d t \leq \int_{0}^{T}\left|u^{\prime}(t)\right|^{2} d t \quad \text { for any } u \in H_{0}^{1}(0, T)
$$

we easily obtain that the norms $\|\cdot\|_{1}$ and $\|\cdot\|_{2}$ are equivalent. Set $X=H_{0}^{1}(0, T) \times H_{0}^{1}(0, T)$. In the Hilbert space $X$, for any $(u, v) \in X$, we set the norm

$$
\|(u, v)\|^{2}=\|u\|_{1}^{2}+\|v\|_{1}^{2} .
$$

By $\left(\mathrm{H}_{1}\right)$, we also introduce the norm

$$
\|(u, v)\|_{X}=\left(\int_{0}^{T}\left(\left|u^{\prime}(t)\right|^{2}+g(t) u^{2}(t)\right) d t+\int_{0}^{T}\left(\left|v^{\prime}(t)\right|^{2}+h(t) v^{2}(t)\right) d t\right)^{\frac{1}{2}} .
$$

We have the following results.

Lemma 2.1 Assume that assumption $\left(\mathrm{H}_{1}\right)$ holds, then, for the Sobolev space $X$, the norm $\|\cdot\|$ and the norm $\|\cdot\|_{X}$ are equivalent.

Proof Since $\alpha>-\lambda_{1}$, there exists $c_{1} \in(0,1)$ such that $-\alpha \leq \lambda_{1}\left(1-c_{1}\right)$. Using Poincaré's inequality, we have

$$
\begin{aligned}
\left(1-c_{1}\right) \int_{0}^{T}\left|u^{\prime}(t)\right|^{2} d t & \geq\left(1-c_{1}\right) \lambda_{1} \int_{0}^{T}|u(t)|^{2} d t \\
& \geq-\alpha \int_{0}^{T}|u(t)|^{2} d t
\end{aligned}
$$

for any $u \in H_{0}^{1}(0, T)$. Thus, we get

$$
\begin{aligned}
\|(u, v)\|_{X}^{2} & =\int_{0}^{T}\left(\left|u^{\prime}(t)\right|^{2}+g(t) u^{2}(t)\right) d t+\int_{0}^{T}\left(\left|v^{\prime}(t)\right|^{2}+h(t) v^{2}(t)\right) d t \\
& \geq c_{1}\left(\|u\|_{1}^{2}+\|v\|_{1}^{2}\right)=c_{1}\|(u, v)\|^{2} .
\end{aligned}
$$

Moreover, one has

$$
\begin{aligned}
\|(u, v)\|_{X}^{2} & =\int_{0}^{T}\left(\left|u^{\prime}(t)\right|^{2}+g(t) u^{2}(t)\right) d t+\int_{0}^{T}\left(\left|v^{\prime}(t)\right|^{2}+h(t) v^{2}(t)\right) d t \\
& \leq\|g\|_{\infty} \int_{0}^{T} u^{2}(t) d t+\|h\|_{\infty} \int_{0}^{T} v^{2}(t) d t+\int_{0}^{T}\left(\left|u^{\prime}(t)\right|^{2}+\left|v^{\prime}(t)\right|^{2}\right) d t \\
& \leq\left(\max \left\{\frac{\|g\|_{\infty}}{\lambda_{1}}, \frac{\|h\|_{\infty}}{\lambda_{1}}\right\}+1\right)\left\|(u, v)^{2}\right\| .
\end{aligned}
$$

Thereby, the norm $\|\cdot\|$ and the norm $\|\cdot\|_{X}$ are equivalent. 
Lemma 2.2 For any $(u, v) \in X$, there exists $c_{2}>0$ such that $\|u\|_{\infty},\|v\|_{\infty} \leq c_{2}\|(u, v)\|_{X}$.

Proof For any $(u, v) \in X$, by the mean value theorem, there exists a constant $\tau \in[0, T]$ such that

$$
u(\tau)=\frac{1}{T} \int_{0}^{T} u(s) d s
$$

Furthermore, using Hölder's inequality and Poincaré's inequality, we have

$$
\begin{aligned}
|u(t)| & =\left|u(\tau)+\int_{\tau}^{t} u^{\prime}(s) d s\right| \\
& \leq \frac{1}{T} \int_{0}^{T}|u(s)| d s+\int_{0}^{T}\left|u^{\prime}(s)\right| d s \\
& \leq T^{-\frac{1}{2}}\|u\|_{L^{2}}+T^{\frac{1}{2}}\left\|u^{\prime}\right\|_{L^{2}} \\
& \leq\left(\left(\lambda_{1} T\right)^{-\frac{1}{2}}+T^{\frac{1}{2}}\right)\left\|u^{\prime}\right\|_{L^{2}} \\
& \leq\left(\left(\lambda_{1} T\right)^{-\frac{1}{2}}+T^{\frac{1}{2}}\right)\|(u, v)\| .
\end{aligned}
$$

Combining Lemma 2.1 and (2.1), there exists $c_{2}>0$ such that

$$
\|u\|_{\infty} \leq c_{2}\|(u, v)\|_{X} .
$$

Similarly, we can get

$$
\|v\|_{\infty} \leq c_{2}\|(u, v)\|_{X} .
$$

In the following, we are concerned with problem (1.1) subject to impulses in the derivative at the prescribed instants $t_{k}, k=1,2, \ldots, m$. We are interested in the solution $(u, v)$ of problem (1.1) satisfying the impulse conditions

$$
\Delta u^{\prime}\left(t_{k}\right)=u^{\prime}\left(t_{k}^{+}\right)-u^{\prime}\left(t_{k}^{-}\right)=I_{k}\left(u\left(t_{k}\right)\right)
$$

and

$$
\Delta v^{\prime}\left(t_{k}\right)=v^{\prime}\left(t_{k}^{+}\right)-v^{\prime}\left(t_{k}^{-}\right)=J_{k}\left(v\left(t_{k}\right)\right), \quad k=1,2, \ldots, m .
$$

For $u, v \in H^{2}(0, T)$, we have that $u, v, u^{\prime}$ and $v^{\prime}$ are both absolutely continuous. Meanwhile, $u^{\prime \prime}, v^{\prime \prime} \in L^{2}(0, T)$. Hence, $u^{\prime}\left(t^{+}\right)=u^{\prime}\left(t^{-}\right)$and $v^{\prime}\left(t^{+}\right)=v^{\prime}\left(t^{-}\right)$for any $t \in[0, T]$. If $u, v \in H_{0}^{1}(0, T)$, then $u, v$ are absolutely continuous and $u^{\prime}, v^{\prime} \in L^{2}(0, T)$. In this case, the one-sided derivatives $u^{\prime}\left(t^{+}\right), u^{\prime}\left(t^{-}\right), v^{\prime}\left(t^{+}\right)$and $v^{\prime}\left(t^{-}\right)$may not exist. Thus, we need to introduce a concept of solution which is different from a classical solution. We say that $(u, v)$ is a classical solution of problem (1.1) if it satisfies the corresponding equations a.e. on [0,T], the limits $u^{\prime}\left(t_{k}^{+}\right), u^{\prime}\left(t_{k}^{-}\right), v^{\prime}\left(t_{k}^{+}\right)$and $v^{\prime}\left(t_{k}^{-}\right), k=1,2, \ldots, m$, exist and (2.2), (2.3) hold.

Taking $(\varphi, \psi) \in X$ and multiplying the two sides of the equalities

$$
-u^{\prime \prime}(t)+g(t) u(t)=f_{u}(u, v)
$$


and

$$
-v^{\prime \prime}(t)+h(t) v(t)=f_{v}(u, v)
$$

by $\varphi$ and $\psi$ respectively, then integrating from 0 to $T$, we have

$$
-\int_{0}^{T} u^{\prime \prime}(t) \varphi d t+\int_{0}^{T} g(t) u(t) \varphi(t) d t=\int_{0}^{T} f_{u}(u(t), v(t)) \varphi(t) d t
$$

and

$$
-\int_{0}^{T} v^{\prime \prime}(t) \psi d t+\int_{0}^{T} h(t) v(t) \psi(t) d t=\int_{0}^{T} f_{v}(u(t), v(t)) \psi(t) d t .
$$

The first terms of (2.4) and (2.5) are now

$$
\begin{aligned}
-\int_{0}^{T} u^{\prime \prime}(t) \varphi d t & =-\sum_{k=0}^{m} \int_{t_{k}}^{t_{k+1}} u^{\prime \prime}(t) \varphi(t) d t \\
& =\sum_{k=1}^{m} I_{k}\left(u\left(t_{k}\right)\right) \varphi\left(t_{k}\right)+\int_{0}^{T} u^{\prime}(t) \varphi^{\prime}(t) d t
\end{aligned}
$$

and

$$
\begin{aligned}
-\int_{0}^{T} v^{\prime \prime}(t) \psi(t) d t & =-\sum_{k=0}^{m} \int_{t_{k}}^{t_{k+1}} v^{\prime \prime}(t) \psi(t) d t \\
& =\sum_{k=1}^{m} J_{k}\left(v\left(t_{k}\right)\right) \psi\left(t_{k}\right)+\int_{0}^{T} v^{\prime}(t) \psi^{\prime}(t) d t .
\end{aligned}
$$

In connection with (2.4), (2.5), (2.6) and (2.7), we have

$$
\begin{aligned}
& \int_{0}^{T} u^{\prime}(t) \varphi^{\prime}(t) d t+\int_{0}^{T} v^{\prime}(t) \psi^{\prime}(t) d t+\int_{0}^{T} g(t) u(t) \varphi(t) d t \\
& \quad+\int_{0}^{T} h(t) v(t) \psi(t) d t+\sum_{k=1}^{m} I_{k}\left(u\left(t_{k}\right)\right) \varphi\left(t_{k}\right)+\sum_{k=1}^{m} J_{k}\left(v\left(t_{k}\right)\right) \psi\left(t_{k}\right) \\
& =\int_{0}^{T} f_{u}(u, v) \varphi(t) d t+\int_{0}^{T} f_{v}(u, v) \psi(t) d t .
\end{aligned}
$$

Based on equality (2.8), we introduce the concept of weak solution for problem (1.1). We say that a pair of functions $(u, v) \in X$ is a weak solution for problem (1.1) if identity (2.8) holds for any $(\varphi, \psi) \in X$. The corresponding energy functional $\Phi$ to problem (1.1) is defined by

$$
\begin{aligned}
\Phi(u, v)= & \frac{1}{2} \int_{0}^{T}\left(\left|u^{\prime}(t)\right|^{2}+g(t) u^{2}(t)\right) d t+\frac{1}{2} \int_{0}^{T}\left(\left|v^{\prime}(t)\right|^{2}+h(t) v^{2}(t)\right) d t \\
& +\sum_{k=1}^{m} \int_{0}^{u\left(t_{k}\right)} I_{k}(t) d t+\sum_{k=1}^{m} \int_{0}^{v\left(t_{k}\right)} J_{k}(t) d t-\int_{0}^{T} f(u, v) d t \\
= & \frac{1}{2}\|(u, v)\|_{X}^{2}+\sum_{k=1}^{m} \int_{0}^{u\left(t_{k}\right)} I_{k}(t) d t+\sum_{k=1}^{m} \int_{0}^{v\left(t_{k}\right)} J_{k}(t) d t-\int_{0}^{T} f(u, v) d t .
\end{aligned}
$$


Combining the continuity of $f_{u}, f_{v}, I_{k}$ and $J_{k}, k=1,2, \ldots, m$, by standard arguments [30], we can show that the functional $\Phi \in C^{1}(X, \mathbb{R})$. Furthermore, we have

$$
\begin{aligned}
\Phi^{\prime}(u, v)(\varphi, \psi)= & \int_{0}^{T} u^{\prime}(t) \varphi^{\prime}(t) d t+\int_{0}^{T} g(t) u(t) \varphi(t) d t \\
& +\int_{0}^{T} v^{\prime}(t) \psi^{\prime}(t) d t+\int_{0}^{T} h(t) v(t) \psi(t) d t+\sum_{k=1}^{m} I_{k}\left(u\left(t_{k}\right)\right) \psi\left(t_{k}\right) \\
& +\sum_{k=1}^{m} J_{k}\left(v\left(t_{k}\right)\right) \psi\left(t_{k}\right)-\int_{0}^{T} f_{u}(u, v) \varphi(t) d t-\int_{0}^{T} f_{v}(u, v) \psi(t) d t .
\end{aligned}
$$

Indeed, we reduce the problem of finding weak solutions of (1.1) to the one of seeking the critical points of the corresponding functional $\Phi$. To this end, we recall some known results from variational method. We say that a minimizing sequence for a functional $F$ : $X \rightarrow \mathbb{R}$ is a sequence $\left\{\left(u_{i}, v_{i}\right)\right\}$ such that

$$
F\left(u_{i}, v_{i}\right) \rightarrow \inf F \quad \text { whenever } i \rightarrow \infty
$$

Lemma 2.3 [36] Let $X$ be a reflexive Banach space and $F: X \rightarrow \mathbb{R}$ be continuously Fréchetdifferentiable. If $F$ is weakly lower semi-continuous and has a bounded minimizing sequence, then $F$ has a minimum on $X$.

\section{Main result}

Lemma 3.1 Assume that conditions $\left(\mathrm{H}_{1}\right)-\left(\mathrm{H}_{3}\right)$ are satisfied. Then the functional $\Phi$ defined by (2.9) is continuously Fréchet-differentiable and weakly lower semi-continuous.

Proof First, using the continuity of $f_{u}, f_{v}, I_{k}$ and $J_{k}, k=1,2, \ldots, m$, we easily obtain the continuity and differentiability of $\Phi$ and $\Phi^{\prime}: X=H_{0}^{1}(0, T) \times H_{0}^{1}(0, T) \rightarrow \mathbb{R}$ defined by (2.10).

In the following, we prove that $\Phi$ is weakly lower semi-continuous. If $\left\{\left(u_{i}, v_{i}\right)\right\} \subset X$ with $\left(u_{i}, v_{i}\right) \rightarrow(u, v)$, then, by Lemma 2.2 , we get that $\left\{u_{i}\right\}$ and $\left\{v_{i}\right\}$ converge uniformly to $u$ and $v$ on $[0, T]$ respectively. In connection with the fact that $\liminf _{i \rightarrow \infty}\left\|\left(u_{i}, v_{i}\right)\right\|_{X} \geq\|(u, v)\|_{X}$, one has

$$
\begin{aligned}
\liminf _{i \rightarrow \infty} \Phi\left(u_{i}, v_{i}\right)= & \liminf _{i \rightarrow \infty}\left\{\frac{1}{2}\left\|\left(u_{i}, v_{i}\right)\right\|_{X}^{2}+\sum_{k=1}^{m} \int_{0}^{u_{i}\left(t_{k}\right)} I_{k}(t) d t\right. \\
& \left.+\sum_{k=1}^{m} \int_{0}^{v_{i}\left(t_{k}\right)} J_{k}(t) d t-\int_{0}^{T} f\left(u_{i}, v_{i}\right) d t\right\} \\
\geq & \frac{1}{2}\|(u, v)\|_{X}^{2}+\sum_{k=1}^{m} \int_{0}^{u\left(t_{k}\right)} I_{k}(t) d t \\
& +\sum_{k=1}^{m} \int_{0}^{v\left(t_{k}\right)} J_{k}(t) d t-\int_{0}^{T} f(u, v) d t \\
= & \Phi(u, v) .
\end{aligned}
$$

This implies that the functional $\Phi$ is weakly lower semi-continuous. 
Proof of Theorem 1.1 For any $(u, v) \in X$, using assumptions $\left(\mathrm{H}_{2}\right),\left(\mathrm{H}_{3}\right)$ and Lemma 2.2, we have

$$
\begin{aligned}
\Phi(u, v)= & \frac{1}{2}\|(u, v)\|_{X}^{2}+\sum_{k=1}^{m} \int_{0}^{u\left(t_{k}\right)} I_{k}(t) d t+\sum_{k=1}^{m} \int_{0}^{v\left(t_{k}\right)} J_{k}(t) d t-\int_{0}^{T} f(u, v) d t \\
\geq & \frac{1}{2}\|(u, v)\|_{X}^{2}-\sum_{k=1}^{m} \int_{0}^{u\left(t_{k}\right)}\left(a_{k}+b_{k}|t|^{\beta_{k}}\right) d t-\sum_{k=1}^{m} \int_{0}^{v\left(t_{k}\right)}\left(a_{k}+b_{k}|t|^{\beta_{k}}\right) d t \\
& -\int_{0}^{T}\left(a|u|+a|v|+b|u|^{\gamma_{1}+1}+b|v|^{\gamma_{2}+1}\right) d t \\
\geq & \frac{1}{2}\|(u, v)\|_{X}^{2}-m A\|u\|_{\infty}-B \sum_{k=1}^{m}\|u\|_{\infty}^{\beta_{k}+1}-m A\|v\|_{\infty} \\
& -B \sum_{k=1}^{m}\|v\|_{\infty}^{\beta_{k}+1}-a T\left(\|u\|_{\infty}+\|v\|_{\infty}\right)-b T\left(\|u\|_{\infty}^{\gamma_{1}+1}+\|v\|_{\infty}^{\gamma_{2}+1}\right) \\
\geq & \frac{1}{2}\|(u, v)\|_{X}^{2}-2 m A c_{2}\|(u, v)\|_{X}-2 B \sum_{k=1}^{m} c_{2}^{\beta_{k}+1}\|(u, v)\|_{X}^{\beta_{k}+1} \\
& -2 a T\|(u, v)\|_{X}-b T c_{2}^{\gamma_{1}+1}\|(u, v)\|_{X}^{\gamma_{1}+1}-b T c_{2}^{\gamma_{2}+1}\|(u, v)\|_{X}^{\gamma_{2}+1},
\end{aligned}
$$

where $A=\max \left\{a_{1}, a_{2}, \ldots, a_{k}\right\}, B=\max \left\{b_{1}, b_{2}, \ldots, b_{k}\right\}$.

In connection with $\gamma_{1}, \gamma_{2}, \beta_{k} \in[0,1), k=1,2, \ldots, m$, it follows that the functional $\Phi$ is coercive on $X$. Furthermore, by Lemma 3.1 and Lemma 2.3, we have that $\Phi$ has a minimum point on $X$. Hence, problem (1.1) has at least one nontrivial solution.

Corollary 3.1 Assume that $f_{u}, f_{v}, I_{k}$ and $J_{k}, k=1,2, \ldots, m$, are bounded. Then problem (1.1) has at least one solution.

\section{Example}

Let $T=\pi, t_{1}=1$. We consider the following problem with impulses:

$$
\left\{\begin{array}{l}
-u^{\prime \prime}(t)+(1+t) u(t)=t^{2}+\sqrt{u(t)}, \\
-v^{\prime \prime}(t)+\left(t+t^{2}\right) v(t)=t+\sqrt[3]{v(t)}, \\
u(0)=u(\pi)=v(0)=v(\pi)=0, \\
\Delta u^{\prime}\left(t_{1}\right)=u^{\prime}\left(t_{1}^{+}\right)-u^{\prime}\left(t_{1}^{-}\right)=2+\sqrt[3]{u\left(t_{1}\right)}, \\
\Delta v^{\prime}\left(t_{1}\right)=v^{\prime}\left(t_{1}^{+}\right)-v^{\prime}\left(t_{1}^{-}\right)=t_{1}+\sqrt[4]{v\left(t_{1}\right)},
\end{array}\right.
$$

First we can see that $g(t)=1+t, h(t)=t+t^{2}$, and $\alpha=0>-\frac{\pi^{2}}{T^{2}}$, then $\left(\mathrm{H}_{1}\right)$ holds. Next, taking $a=\pi^{2}, b=1, \gamma_{1}=\frac{1}{2}$, and $\gamma_{2}=\frac{1}{3},\left(\mathrm{H}_{2}\right)$ holds. Finally, taking $a_{1}=2, b=1$, and $\beta_{1}=\frac{1}{3}$, $\left(\mathrm{H}_{3}\right)$ holds. Then, by Theorem 1.1, the impulsive problem (4.1) has at least one nontrivial solution.

The authors declare that they have no competing interests. 


\section{Acknowledgements}

The author would like to thank the referees very much for their helpful comments and suggestions. This work was supported by the National Natural Science Foundation of China (11271364).

Received: 29 June 2015 Accepted: 18 September 2015 Published online: 30 September 2015

\section{References}

1. Haddad, WM, Chellaboina, C, Nersesov, SG, Stability, GS: Dissipativity and Control. Princeton University Press, Princeton (2006)

2. Lakshmikantham, V, Bainov, DD, Simeonov, PS: Theory of Impulsive Differential Equations. World Scientific, Singapore (1989)

3. Agarwal, RP, Franco, D, O'Regan, D: Singular boundary value problem for first and second order impulsive differential equations. Aequ. Math. 69, 83-96 (2005)

4. Ahmad, B, Nieto, JJ: Existence and approximation of solutions for a class of nonlinear impulsive functional differential equations with anti-periodic boundary conditions. Nonlinear Anal. TMA 69, 3291-3298 (2008)

5. Hernandez, E, Henriquez, HR, McKibben, MA: Existence results for abstract impulsive second-order neutral functional differential equations. Nonlinear Anal. TMA 70, 2736-2751 (2009)

6. Li, J, Nieto, JJ, Shen, J: Impulsive periodic boundary value problems of first-order differential equations. J. Math. Anal. Appl. 325, 226-236 (2007)

7. Luo, Z, Nieto, JJ: New results for the periodic boundary value problem for impulsive integro-differential equations Nonlinear Anal. TMA 70, 2248-2260 (2009)

8. Nieto, JJ: Basic theory for nonresonance impulsive periodic problems of first order. J. Math. Anal. Appl. 205, 423-433 (1997)

9. Nieto, JJ, Rodríguez-López, R: Periodic boundary value problem for non-Lipschitzian impulsive functional differential equations. J. Math. Anal. Appl. 318, 593-610 (2006)

10. Samoilenko, AM, Perestyuk, NA: Impulsive Differential Equations. World Scientific, Singapore (1995)

11. Braverman, E, Zhukovskiy, S: The problem of a lazy tester, or exponential dichotomy for impulsive differential equations revisited. Nonlinear Anal. Hybrid Syst. 2, 971-979 (2008)

12. Dai, B, Su, H, Hu, D: Periodic solution of a delayed ratio-dependent predator-prey model with monotonic functional response and impulse. Nonlinear Anal. TMA 70, 126-134 (2009)

13. Del Pino, $M$, Elgueta, $M$, Manasevich, $R$ : A homotopic deformation along $p$ of a Leray-Schauder degree result and existence for $\left(\left|u^{\prime}\right|^{p-2} u^{\prime}\right)^{\prime}+f(t, u)=0, u(0)=u(T)=0, p>1^{*}$. J. Differ. Equ. 80, 1-13 (1989)

14. Guo, H, Chen, L: Time-limited pest control of a Lotka-Volterra model with impulsive harvest. Nonlinear Anal., Real World Appl. 10, 840-848 (2009)

15. Jiang, G, Lu, Q, Qian, L: Complex dynamics of a Holling type II prey-predator system with state feedback control. Chaos Solitons Fractals 31, 448-461 (2007)

16. Jiang, G, Lu, Q, Qian, L: Chaos and its control in an impulsive differential system. Chaos Solitons Fractals 34, 1135-1147 (2007)

17. Mohamad, S, Gopalsamy, K, Akca, H: Exponential stability of artificial neural networks with distributed delays and large impulses. Nonlinear Anal., Real World Appl. 9, 872-888 (2008)

18. Pei, Y, Li, C, Chen, L, Wang, C: Complex dynamics of one-prey multi-predator system with defensive ability of prey and impulsive biological control on predators. Adv. Complex Syst. 8, 483-495 (2005)

19. Shen, J, Li, J: Existence and global attractivity of positive periodic solutions for impulsive predator-prey model with dispersion and time delays. Nonlinear Anal., Real World Appl. 10, 227-243 (2009)

20. Wang, W, Shen, J, Nieto, Jj: Permanence and periodic solution of predator-prey system with Holling type functional response and impulse. Discrete Dyn. Nat. Soc. 2007, Article ID 81756 (2007)

21. Wei, C, Chen, L: A delayed epidemic model with pulse vaccination. Discrete Dyn. Nat. Soc. 2008, Article ID 746951 (2008)

22. Xia, Y: Positive periodic solutions for a neutral impulsive delayed Lotka-Volterra competition system with the effect of toxic substance. Nonlinear Anal., Real World Appl. 8, 204-221 (2007)

23. Yan, J, Zhao, A, Nieto, JJ: Existence and global attractivity of positive periodic solution of periodic single-species impulsive Lotka-Volterra systems. Math. Comput. Model. 40, 509-518 (2004)

24. Zeng, G, Wang, F, Nieto, JJ: Complexity of delayed predator-prey model with impulsive harvest and Holling type II functional response. Adv. Complex Syst. 11, 77-97 (2008)

25. Zhang, $\mathrm{H}, \mathrm{Chen}, \mathrm{L}$, Nieto, JJ: A delayed epidemic model with stage structure and pulses for management strategy. Nonlinear Anal., Real World Appl. 9, 1714-1726 (2008)

26. Zhang, H, Xu, W, Chen, L: An impulsive infective transmission SI model for pest control. Math. Methods Appl. Sci. 30 1169-1184 (2007)

27. Zhou, J, Xiang, L, Liu, Z: Synchronization in complex delayed dynamical networks with impulsive effects. Physica A 384, 684-692 (2007)

28. Carter, TE: Necessary and sufficient conditions for optional impulsive rendezvous with linear equations of motions. Dyn. Control 10, 219-227 (2000)

29. Liu, X, Willms, AR: Impulsive controllability of linear dynamical systems with applications to maneuvers of spacecraft. Math. Probl. Eng. 2, 277-299 (1996)

30. Rabinowitz, PH: Minimax Methods in Critical Point Theory with Applications to Differential Equations. CBMS Reg. Conf. Ser. Math., vol. 65. Am. Math. Soc., Providence (1986)

31. Tian, Y, Ge, W: Applications of variational methods to boundary value problem for impulsive ordinary differential equations. Proc. Edinb. Math. Soc. 51, 509-527 (2008)

32. Nieto, JJ, O'Regan, D: Variational approach to impulsive differential equations. Nonlinear Anal., Real World Appl. 10, 680-690 (2009)

33. Zhang, H, Li, ZX: Variational approach to impulsive differential equations with periodic boundary conditions. Nonlinear Anal., Real World Appl. 11, 67-78 (2010) 
34. Zhang, ZH, Yuan, R: An application of variational methods to Dirichlet boundary value problem with impulses. Nonlinear Anal., Real World Appl. 11, 155-162 (2010)

35. Zhou, JW, Li, YK: Existence and multiplicity of solutions for some Dirichlet problems with impulsive effects. Nonlinear Anal. TMA 71, 2856-2865 (2009)

36. Mawhin, J, Willem, M: Critical Point Theory and Hamiltonian Systems. Springer, New York (1989)

Submit your manuscript to a SpringerOpen ${ }^{\circ}$ journal and benefit from:

- Convenient online submission

- Rigorous peer review

- Immediate publication on acceptance

Open access: articles freely available online

- High visibility within the field

- Retaining the copyright to your article 